\title{
Corrigendum to "High-Dose Subcutaneous Immunoglobulins for the Treatment of Severe Treatment-Resistant Polymyositis"
}

\author{
Patrick Cherin, ${ }^{1}$ Jean-Christophe Delain, ${ }^{2}$ Jean-Charles Crave, ${ }^{2}$ and Odile Cartry ${ }^{3}$ \\ ${ }^{1}$ Department of Internal Medicine, Pitié-Salpetrière Hospital Group, 47-83 Boulevard de l'Hôpital, 75013 Paris, France \\ ${ }^{2}$ Octapharma, 92100 Boulogne-Billancourt, France \\ ${ }^{3}$ Clinique Mutualiste Catalane, 66000 Perpignan, France
}

Correspondence should be addressed to Patrick Cherin; patrick.cherin@psl.aphp.fr

Received 5 March 2015; Accepted 29 March 2015

Copyright (c) 2015 Patrick Cherin et al. This is an open access article distributed under the Creative Commons Attribution License, which permits unrestricted use, distribution, and reproduction in any medium, provided the original work is properly cited.

In the paper titled "High-Dose Subcutaneous Immunoglobulins for the Treatment of Severe Treatment-Resistant Polymyositis," the authors were cited as "Cherin Patrick, Delain Jean-Christophe, Crave Jean-Charles, and Cartry Odile." This is now replaced by the correct names as above. 


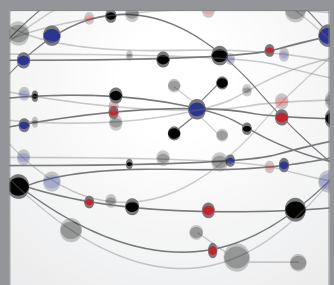

The Scientific World Journal
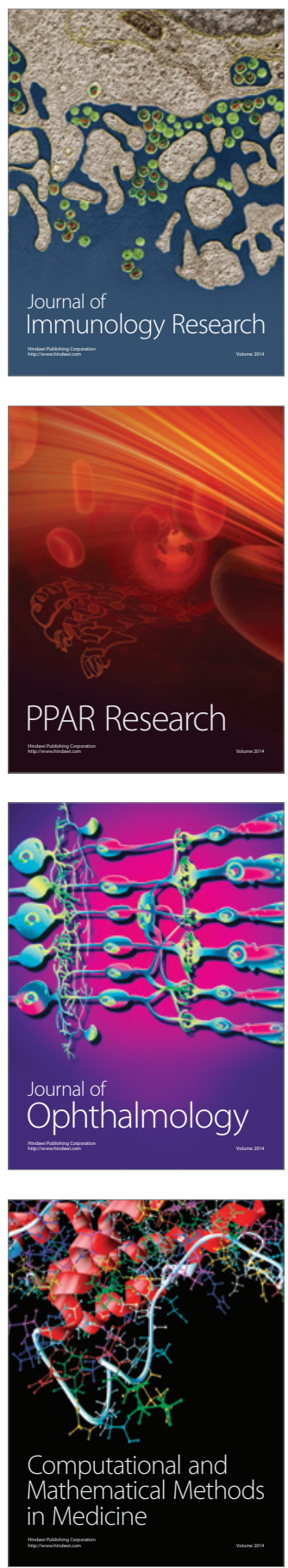

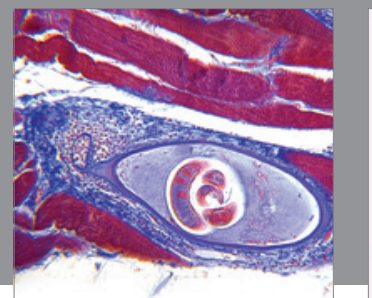

Gastroenterology

Research and Practice
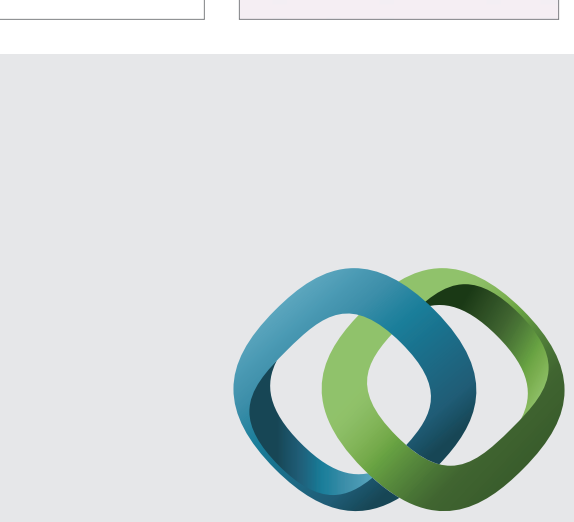

\section{Hindawi}

Submit your manuscripts at

http://www.hindawi.com
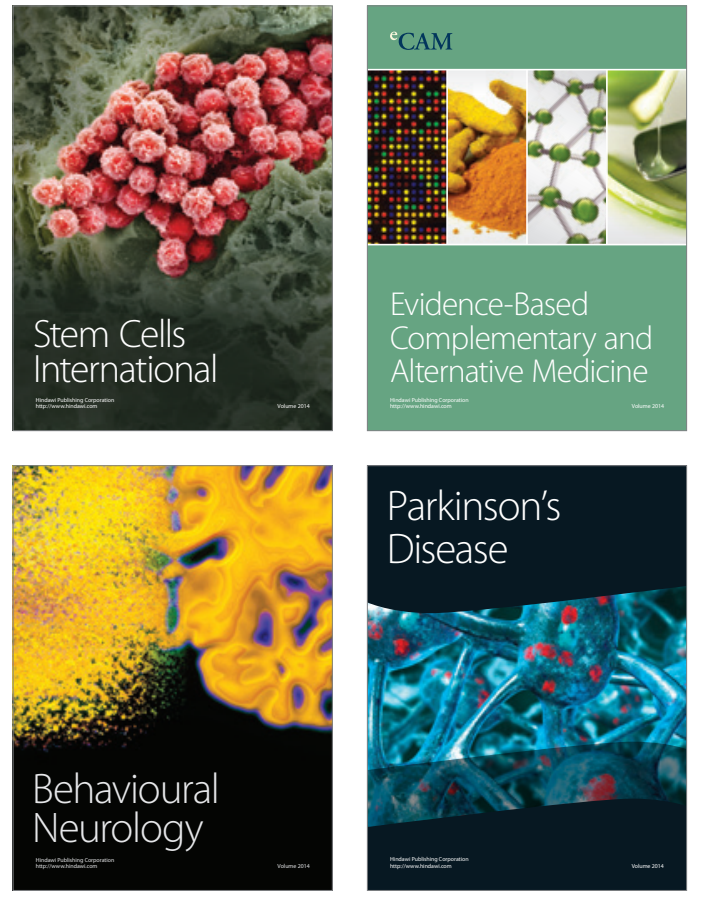
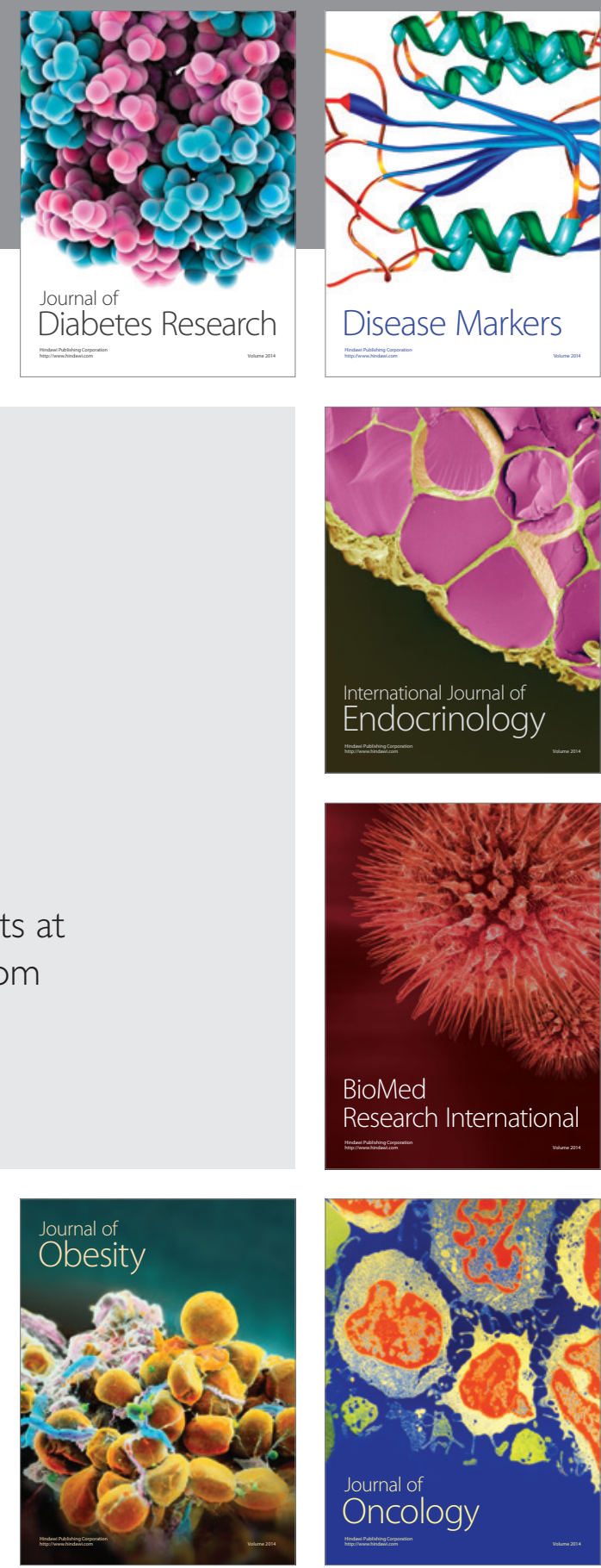

Disease Markers
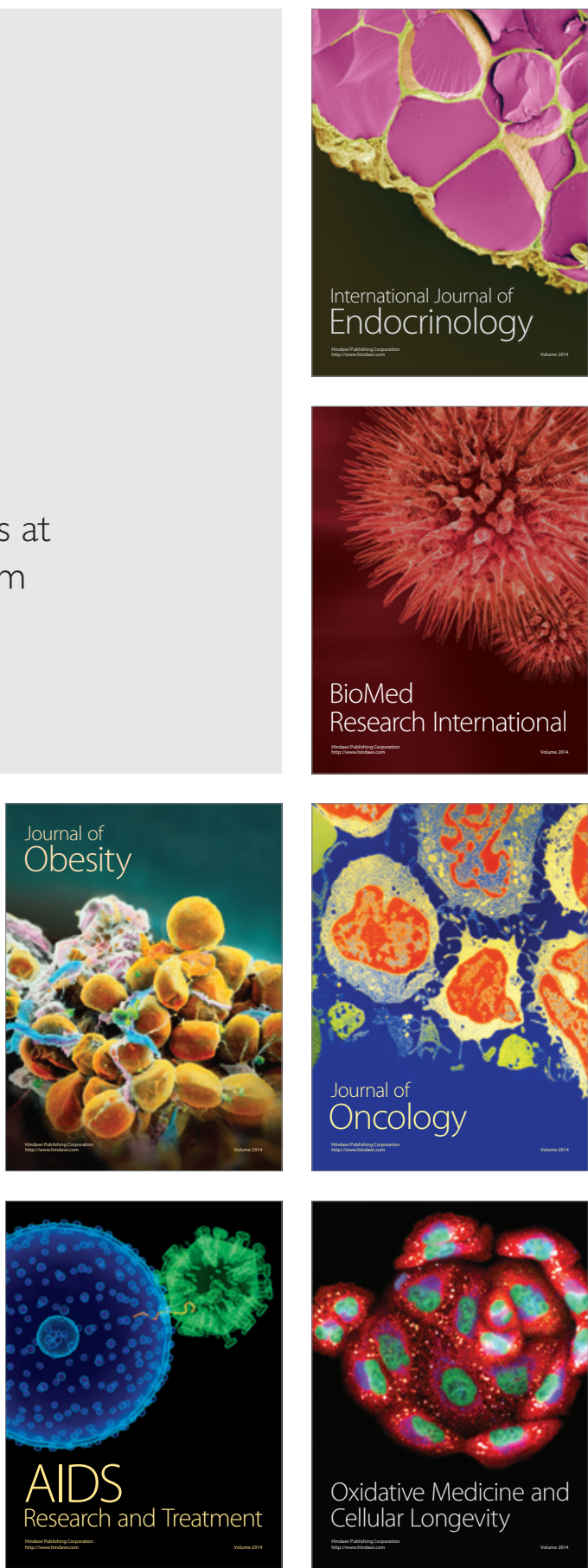